\title{
Research on the Protection Predicament and Digital Breakthrough Path of Rural Architecture in Shandong
}

\author{
Qiang Liu ${ }^{1, \text { a }}$, Nan $\mathrm{Shi}^{* 1, \mathrm{~b}}$ \\ ${ }^{1}$ School of Civil Engineering and Architecture University of Jinan Jinan, China
}

\begin{abstract}
Rural architecture, as an important carrier of rural areas, faces the huge impact of modern life style and construction mode, and there is a crisis of cognitive degradation and loss of skills. With the continuous promotion of rural revitalization, the crisis of its protection and inheritance is increasingly serious, and the disadvantages of the single inheritance mode of oral transmission and personal transmission are also gradually revealed. In this predicament, how to innovate the inheritance of traditional skills has become an urgent problem to be solved. In the era when digital technology has penetrated into every field of modern life and become a technology booster, this paper intends to use digital technology and take the construction technology of rural architecture in Shandong province as the entry point to solve the dilemma faced by rural architecture and study the effective way of its digital inheritance and development.
\end{abstract}

\section{Introduction}

Currently, under the promotion of national policies, rural construction activities in Shandong have increased. As an important carrier of countryside, rural architecture is in an embarrassing situation as it cannot stand alone in the flood of construction: skills are losing, forms are unfounded, literature researches are lacking, some local governments are forced to imitate the Hui-style with horse-head wallstyle buildings in rural construction. The main reason is that domestic scholars have relatively insufficient researches on Shandong's rural construction, leading to the lack of relevant literature and data. And due to a single skill inheritance, the number of craftsmen who master traditional construction and repairing techniques is decreasing year by year. When implementing the project of rural construction protecting and repairing, local governments and architects have no evidence and no human resources to turn to. While part of the new buildings in rural areas are directly adapting the southern styles, completely losing the regional expression of rural construction and the inheritance of the rural context. After the proposal of realizing the great revival of Chinese traditional culture in 2025, and the Shandong government's proposal to build a rural architecture system of "Lu Style" that highlights the traditional characteristics of the province in 2025 , this research applies the digital method to construct the new inheritance system. Taking the construction techniques of Shandong's rural buildings as starting point, this research uses a digital technique to carry out research on the inheritance system and utilization approaches, to solve the problems of protection and inheritance of rural buildings, to dock the actual problems in rural construction, and finally to inspire rural construction and revival in the background of China's new urbanization [1].

\section{Current status of relevant research progress both at home and abroad}

\subsection{Research status abroad}

Amos Rapoport's (1969) work "House Form and Culture" officially marked that the study of rural construction became a discipline in the Western. And then researches and protection on rural construction became increasingly active in the field of international cultural heritage protection, and multidisciplinary research has been maintained for long. Representative scholar Paulo Liver (1997) wrote the book "Encyclopedia of Vernacular Architecture of the World", which involves a multidisciplinary research perspective and accelerates the general development of the research. And later, more and more scholars have studies on construction techniques from the perspectives of architecture, art and ecology. In terms of digital inheritance of vernacular architecture, in 1996, Japan included rural architecture in the "Cultural Property Protection Law", protecting it as cultural heritage and digital protection work are tried to carry out. Takeo Ojika (2007) used digital restoration to protect the ancient village. Eugene (2019) thought that in the digital era, cultural heritage can be passed on and shared digitally.

\subsection{Research status at home}

Researches on domestic rural architecture. In our country, researches on rural architectures started from traditional dwellings. Liu Dunzhen's “Introduction to Chinese 
Housing" (1953) discusses the historical development process of our country's residential architecture. Taking village investigation as a typical method, Chen Zhihua and Lou Qingxi (1989) introduced theories of different disciplines into the perspective of rural architecture (Pan $\mathrm{Xi}, 2014)$, promoting the development of research work. Shan Jixiang(2010) pointed out the current problems of rural architecture. Many scholars have studied and traced southern rural architecture from different perspectives such as woodcarving decoration, oil painting and wooden construction (Yang Jing, 2015; Pei Qiangqiang, 2016), Li Zhen (2016) proposed to establish a genealogy and database of construction techniques. Gao Qi (2019) pointed out that traditional techniques need innovation. Pan Lusheng suggested to build a comprehensive framework based on computers and to achieve protection work by using digital method (2006). Jia Xiuqing pointed out that digital methods should move from basic protection to inheritance research (2012). Some scholars researched on the digital communication channels and target groups of traditional brick carving techniques, believing that the inheritance model should conform to the development of the times (Li Yujie, 2019).

\subsection{A review of the current status of Shandong rural architecture}

Scholars at home and abroad have conducted researches on rural architecture from different perspectives and methods, and it shows that there are many achievements but still some shortcomings: First, the existing research areas in China are more focused on the south and less on Shandong. Second, the existing researches are mostly carried out from a single perspective such as architecture form and techniques, but less researches on the genealogy of construction techniques and inheritance system. Third, in the traditional Chinese architecture construction system, "oral teaching" has always been the main way to pass on the traditional techniques of construction [2], craftsmen form systematic construction formulas through learning, coping, practicing [3]. However, with the development of technologies, the disadvantages of this single inheritance model are gradually exposed. In the background of digital era and big data, digital inheritance, communication and utilization of Shandong's rural architecture are relatively lagging, and the innovation is insufficient. Therefore, this article takes the construction techniques as starting point, pedigree as the focus, database as the carrier, inheritance as the goal and makes the research with digital methods.

\section{Value of this research}

\subsection{Academic value}

Rural architecture is an important carrier for highlighting rural vitality and rural culture. There are many great rural architecture, construction techniques and architecture forms in Shandong area, but due to the difference in the depth of research results between the north and the south by the ancestors, and the limitation of objective research conditions at the time, resulting in the situation that the traditional architecture history emphasizes on the official style rather than the rural local, on the form and style rather than the techniques and craftsmanship [4]. And with the single inheritance model becoming more and more prominent with the changes of the time, the traditional techniques are facing the danger of losing, the traditional system are facing the danger of departing. This research can make up for the above shortcomings, strengthen the academic basic research, make up for the insufficiency of researches on Shandong's architecture history, and push forward the breadth and depth of the Chinese architecture history research through the research on the inheritance system context and the research on the genealogy of the construction techniques.

\subsection{Realistic value}

a) Digital method expands the breadth of inheritance and the dimension of communication, which rescues and protects the construction techniques that are on the edge of loss.

b) The establishment of database and the digital application can not only provide scholars with professional academic data inquiries, but also provide a platform for popularization of science for the public, improve cultural cognition, enhance cultural selfconfidence and realize cultural power. At the same time, it helps the locals to make appropriate rural architecture protection guidance, and will provide strong data resource support for the provincial government's proposal to create "Lu Style Architecture with Regional Characteristics in Shandong" in 2025, thereby enriching the composition of Chinese architecture style system.

\section{Main research content}

\subsection{The problems of rural architecture in Shandong}

Rural constructions in different regions in Shandong have different forms, construction modes, architecture cultures and humanistic cultures. The construction mode of "sea grass house" along the coast and the stones houses in the middle mountain areas of Shandong are very different. Such regional traditional construction techniques are "spontaneous", its generation and development are derived from actual use needs. To make clear of the construction technologies, techniques and humanistic composition, it is necessary to research thoroughly on regional village constructions in Shandong, such as the layout, street and lane scale, building forms, construction techniques and building materials, and conduct data collection and classification. By combining and excavating the rural architecture in Shandong and integrating the existing research results, this study analyzes the deficiencies and problems in the protection, inheritance, and utilization of the rural architecture in Shandong, laying the foundation for the next step of research. 


\subsection{Genealogy research with the goal of inheritance}

A large number of rural architectures in our country show the colorful traditional style and regional features, and are rich in the cultural "genes" of local buildings. However, the realistic situation of weak locality of protection theory has caused great dilemma to heritage protection. To rescue these rural architecture heritages, it is necessary to firstly sort out the pedigree of rural architecture from a macro perspective.

Through field survey, mapping, interviews and image collection, the collected documents, mapping data and image data are archived according to regions and building types, and their wooden techniques, oil painting techniques, construction customs are classified and studied; this paper further analyzes the differentiated construction modes of different regions horizontally, forming the regional division and genealogical framework of techniques. And then it conducts a longitudinal research on the inheritance and evolution of techniques, thereby forming the rural architecture genealogy from construction techniques, building forms, materials and other modules.

\subsection{Digitization of the crafting process with the goal of inheritance}

Establish a database of rural architecture in Shandong, digitally store the forms, colors and constructing materials by classification and regions; at the same time, perform 3D animation simulation and decomposition of the traditional technique process; realize 3D architecture roaming, VR virtual reality immersive experience to classic rural architectures; and finally achieve digitization of data collection, data analysis, architecture drawing, modeling, technique processing and experiencing.

\subsection{Research on the development, dissemination and utilization of application platforms with the goal of digital inheritance}

Complete the application platform construction through the establishment, design, development of the back-end database, intermediate business logic layer and front-end application layer. Establish an audience-centered communication and utilization system by analyzing the needs of different audiences in the process of information searching and acceptance. To fully utilize the dissemination role of digital method by accessing cloud platforms, Wechat App, etc. to make it serve the scholars, designers, governments and the public.

\section{Thoughts and methods of the research}

\subsection{Thoughts of the research}

Firstly, this paper classifies and sorts out the rural architectures by region; then through field surveys and interviews, typical rural architecture mapping and digital collection of its construction techniques, the paper focuses on the digital inheritance and summarizes the technical genealogy, and establishes a database. Finally, from the perspective of digital utilization, animation is used to stimulate the technical process, application is developed to serve the public.

\subsection{Discussion on research methods}

1)Field research method: field research method will run through all the stages of this project. At the initial stage, the distribution of rural architectures in Shandong will be the research scope; after grasping certain documents, firsthanded materials will be recorded by scientific methods, such as communicating with villagers, questionnaires, mapping the typical architecture cases according to different architecture types.

2)Typological method: classify the collected data into typological first-class classification according to regions, ages, architecture types, etc.; make second-class classification according to wood construction techniques, oil painting techniques, stone and soil stacking techniques, construction customs, etc.; then make typological thirdclass classification according to videos and audios, images, literature and expert database, etc.; and lastly establish a complete framework system.

\section{Key points of the research}

Analysis on the construction techniques and its genealogy of Shandong's rural architecture. The study of construction techniques can break away from the onesided opinion that identifies buildings by forms and colors. The establishing process of construction techniques and its genealogy is the result of specific historical times, natural environment, humanities and other multiple factors, it is not only the main theme of rural architectures, but also includes the changes and inheritance of regional culture and social structure. So this content is the research theme of the project inheritance content, also an important method to clarify the types, causes and inheritance path of rural architecture in Shandong.

Research on the construction of application platforms and the creative use of application methods. China is at the stage of rapid development of digitization and big data application. Digital application and relevant product forms are gradually being widely used by the public. New media represented by Web 3.0, mobile App and mobile catalysts become an important part in constructing and disseminating the national soft power. Its advantages of maximizing interpersonal communication and multidimensional dissemination of technology and culture will benefit the integration of the latest technology and communication channels, making the inheritance and expression of rural culture heritages more vivid. And they are the effective platforms for spreading the national culture in the context of new media. This content is an important carrier and approach of realizing the research on project inheritance content. 


\section{Main arguments}

In the background of information and big data, it is necessary to establish a protection strategy centered on inheritance, and an application strategy that takes creative utilization as the bond, to digitally inherit and creatively use the traditional techniques. Digital information acquisition and processing technologies can better collect, organize and preserve rural architecture data and information. Digitization can break through the fidelity effect, inheritance effect and the scope of inheritance that cannot be achieved by traditional technologies. Cultural heritage protection should not only focus on protection, but also on passing it to the next generation. Only through effective communication, positive publicity, can more people know about cultural heritages, recognize cultural heritages and then actively participate in the protection of cultural heritages, so that cultural heritage can gain lasting vitality. This is also the great chance for the revival of traditional construction techniques

\section{Conclusion}

This paper discusses the predicaments faced by rural architectures in Shandong Province, and theoretically suggests to solve the problem with digital method, and to establish the concept of Shandong rural architecture database. The process of building up the database does not only systematically sort out the rural architectures in Shandong area, but also uses the digital method for data collection, storage, images and animation of traditional techniques to imitate the process of rural architecture construction. It does not only solve the problem of single inheritance, consolidates the data of rural architecture in Shandong area, make up for the insufficiency of research on rural architecture in Shandong's constructional history, but also contributes to the protection and supervision of great rural buildings, and have a positive guiding significance for the protection and inheritance of rural architecture and the construction of new village in Shandong.

\section{Acknowledgment}

This work was funded by the key Research and Development program of Social Science Plan Foundation of Shandong Province(19CWYJ03).

\section{References}

1. Chen Keshi. Researching on Rural Revival Mode of Art Involvement of Community Building [J]. Urban Development Studies, 2016 (02): 57-63.

2. Wang Yuan. Discussion on the Application of the Method of "Oral History" in the Study of Architecture History-A Case Study of the Residential Buildings in Southwest Zhejiang [J]. Journal of Tongji University (social science), 2009, 20(5): 52-56..

3. Wu Dinghang. Oral Tradition in the Construction of Chinese Traditional Architecture [M]. Shanghai:
Tongji University Press, 2019: 247-251.

4. Li Zhen. Research on the Regionalization and Genealogy of Traditional Construction Techniques in Southern China: Reference to the Theory and Method of Communication [J]. Heritage Architecture, 2018 (03): 16-21

5. Wang Xueru. The Study of the Traditional Architecture Construction Techniques in the Mountainous Area of Central Shandong Province [D]. Shandong Architecture University, 2019. 